\title{
A Review of the Optimization of Length of Capillary Tube for a Vapor Compression Refrigeration System
}

\author{
Ms. K. P. Bhangale ${ }^{1}$, Mr. M. M. Deshmukh ${ }^{2}$ \\ ${ }^{1}$ PG Student, Mechanical Engineering, Government College of Engineering, Amrawati \\ ${ }^{2}$ Professor, Mechanical Engineering, Government College of Engineering, Amrawati
}

Received on: 20 February, 2021, Revised on: 23 March, 2021, Published on: 28 March, 2021

\begin{abstract}
Vapor Compression refrigeration system is most commonly available system in day to day life from home to malls in India. It is necessary to improve the performance of system. The study is mainly focus on the improvement of performance. Out of different parameter, the literature review covers the effect of capillary tube on the performance of system. It covers the experimental and numerical study on effect of capillary tube. The results of straight and helical type of capillary tubes are studied. The study also covers the CFD analysis for the different length and diameters of capillary tubes and find out the optimize size.
\end{abstract}

Keywords - Capillary Tube, Condenser, Refrigeration effect, CFD.

\section{I- INTRODUCTION}

\footnotetext{
C apillary tubes have been investigated in detail for many decades. A capillary tube is a common expansion device used in small sized refrigeration and air-conditioning systems. A capillary tube is a constant area expansion device used in a vapor-compression refrigeration system located between the condenser and the evaporator and
}

whose function is to reduce the high pressure in the condenser to low pressure in the evaporator. The capillary tube expansion devices are widely used in refrigeration equipment, especially in small units such as household refrigerators, freezers and small air conditioners. Its simplicity is the most important reason to continue using it instead of other expansion devices. Capillaries substitute for more expensive and complex thermostatic valves. For instance, capillary tubes are used in some complex cooling Systems for particle detectors installed. Nevertheless, one can find other reasons for their Use in highly specialized cooling circuits.

In fact the flow through capillary tube is actually adiabatic not an isenthalpic. In adiabatic capillary tube, the refrigerant expands from high pressure side to low pressure side with no heat exchange with the surroundings. The refrigerant often enters the capillary in a sub cooled liquid state. As the liquid refrigerant flows through the capillary, the pressure drops linearly due to friction while the temperature remains constant. As the pressure of refrigerant falls below the saturation pressure a fraction of liquid refrigerant flashes into vapor. The fluid velocity increases because of the fall in density of the refrigerant 


\section{International Journal of Innovations in Engineering and Science, www.ijies.net}

due to vaporization. Thus, the entire capillary tube length seems to be divided into two distinct regions. The region near the entry is occupied by the liquid phase and the other as the two-phase liquid vapor region.

In the present investigation, an attempt is made to analyze the flow Analysis of the refrigerant inside a capillary tube with different length and diameter for adiabatic flow conditions. The proposed model can predict flow characteristics in adiabatic capillary tubes for a given mass flow rate. In the present study R-600a has been used as a working fluid inside the capillary tube and used the same model to study the flow characteristics of refrigerant in ANSYS CFX software. It is proposed to study the effect and use of different length and diameter of capillary tube and find out the optimum combination which gives higher effect.

\section{II-LITERATURE REVIEW}

Abhinav Kulmitra et al.[1] has studied numerically the use of capillary tube in the mostly in the refrigerant flow control devices. Hence performance of the capillary tube is best for good refrigerant flow. In his work analyze the flow analysis of the refrigerant inside a capillary tube for adiabatic flow conditions. Author has proposed model can predict flow characteristics in adiabatic capillary tubes for a given mass flow rate. In his work R-22 is replaced by Ammonia refrigerant has been used as a working fluid inside the capillary tube and the capillary tube design is changed straight to coiled capillary. The analysis is done in ANSYS CFX 16.2 software. It was observed from the results dryness fraction by using the helical capillary tube (Ammonia refrigerant flow) is better than straight and existing helical capillary tube (R22 refrigerant flow).

Raja $\mathrm{Y}$ et al. [2] presents in investigation for attempt to analyze the flow Analysis of the refrigerant inside a straight capillary tube and coiled capillary tube for adiabatic flow conditions. The given model predicts flow characteristics in adiabatic capillary tubes for a given mass flow rate. In the study R-22 has used as a working fluid inside the straight capillary tube and coiled capillary tube of diameter 1.27 $\mathrm{mm}$ and used the same model to study the flow characteristics of refrigerant in ANSYS CFX software. It was observed from the results dryness fraction by using the helical capillary tube was better than straight capillary tube. The best suitable helical coiled design is suggested.

Chetan Kumar et al. [3] were worked to improve the Coefficient of Performance, It was to require that and Refrigerating Effect Should Increase and Compressor Work should decrease. Experimental analysis on vapor compression refrigeration (VCR) system with ammonia refrigerant was completed and their results were discussed. The effects of the main parameters of performance analysis such as super heating on the refrigerating effect, power required to run the compressor for various evaporating temperatures, mass flow of refrigerant, percentage increase in COP, coefficient of performance (COP). The results from vapor compression refrigerant plant was taken where the variables like suction pressure of compressor, delivery pressure of compressor, temperature of evaporator and condenser were noted and coefficient of performance was calculated. The results obtained was validated through CFD simulation. Further diffuser has been introduced in between compressor and condenser so that power input to the compressor has been reduced there by enhancing COP The enhancement was done through CFD simulation; Modeling and meshing will be done in ICEMCFD, analysis in CFX and post results in CFD POST.

Buddha Chouhan et al [4] has used capillary tubes as expansion device in low capacity refrigeration machines like domestic refrigerators and window type air conditioners. The advantages of the capillary tube over other expansion devices are simple, inexpensive and cause compressor to start at low torque as the pressure across the capillary tube equalize during the off-cycle. The flow characteristics of refrigerants through capillary tubes have been studied extensively in past six decades, both experimentally and analytically, most of these studies mainly focused on straight capillary tubes. In this thesis, the effects of the relevant parameters on the flow characteristic of R134a and R-22 flowing through adiabatic helical capillary tubes were experimentally studied. The capillary tubes' diameter, coil diameter, and parameters relating to flow conditions such as inlet pressures and degree of sub cooling were the major parameters investigated. In this thesis, the CFD analysis is to determine the heat transfer rate, pressure drop, velocity, mass flow rate and heat transfer coefficient for the fluids R134A and R-22 with different tube and coil diameters. Thermal 


\section{International Journal of Innovations in Engineering and Science, www.ijies.net}

analysis is to determine the temperature distribution and heat flux for copper and aluminum as tube materials.3D modeling is done pro-engineer and analysis is done in ANSYS software.

Narendra Yadav et al. [5] used capillary tube mostly in the refrigerant flow control devices. Hence performance of the capillary tube should be good for smooth refrigerant flow. Many researchers worked in these area by experimentally and analytically. In this present work analyse the flow analysis of the refrigerant inside a capillary tube for adiabatic flow conditions. The proposed model has predict flow characteristics in adiabatic capillary tubes for a given mass flow rate. In the current work R-22 is replaced by Ammonia refrigerant has been used as a working fluid inside the capillary tube and the capillary tube design is changed straight to coiled capillary, which taken from good literature. The analysis is done in ANSYS CFX 16.2 software. It is observed from the results dryness fraction by using the helical capillary tube (Ammonia refrigerant flow) is better than straight and existing helical capillary tube (R22 refrigerant flow). The best suitable helical coiled design is suggested.
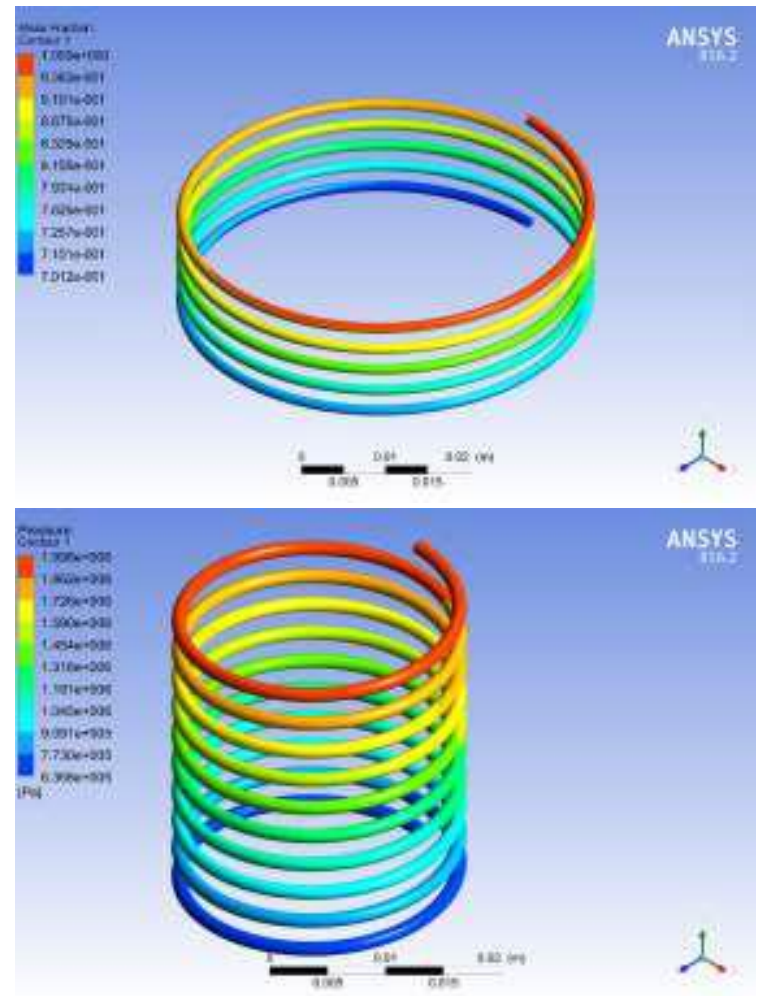

Fig 1-Pressure contours of helical coiled capillary tube
Oyedepo et. al. [6] has done a comparative study on experimental performance of a domestic refrigerator using R600A and LPG with a varying refrigerant charge (wr) and capillary tube length $(\mathrm{L})$. The enthalpy of the refrigerants R600A and LPG for each data set for the experimental conditions were obtained by using REFPROP software (version 9.0). The results show that the design temperature and pull-down time set by ISO for a small refrigerator were achieved earlier using refrigerant charge $60 \mathrm{~g}$ of LPG with a $1.5 \mathrm{~m}$ capillary tube length. The highest COP (4.8) was obtained using $60-\mathrm{g}$ charge of LPG with L of $1.5-\mathrm{m}$. The average COP obtained using LPG was $1.14 \%$ higher than that of R600A. Based on the result of electric power consumption, R600A offered lowest power consumption. The compressor consumed $20 \%$ less power compared to LPG in the system. The system performed best with LPG in terms of COP and cooling capacity, while in terms of power consumption R600A performed best.

Reddy et al. [7] present work the experimental investigation of a household $\mathrm{r}$ refrigerator was calculated by simultaneously changing the refrigerant charge $(\mathrm{mr})$ and length of capillary tube (Lc).The recent literature review shows the consistent research in the field of new refrigerants for usage in the refrigeration and air conditioning systems due to increased need and importance on the climate change effects faced by the humankind. The recent decades show the replacement of CFCs with HFCs, later with mixture of HFCs. But the high GWP value of HFCs paved the way for the development of new refrigerants using Hydrocarbons or hydrocarbon mixtures. The present paper presents the experimental investigations on the domestic refrigerator using two different hydrocarbon mixtures, viz., R550/50(R290/R600a) and R436Awith mass fraction of 56/44of R290 and R600a. The experiments are conducted by changing the refrigerant charge (mr) and length of capillary tube (LC) at different evaporator temperature (Te).Continuous consecutively and cycling tests are performed on the refrigerator under steady state situations. The pressure at the inlet and outlet of the compressor are note down and evaluated as well as the temperature readings can be observed at various positions in the refrigerator. And also the pull down time is noted for the three different refrigerants for varying refrigerant charge and length of capillary and graphs are plotted. The results show $\mathrm{t}$ that the design temperature of $-150 \mathrm{C}$ (according to IS1476 part1) and pull down time of 90 


\section{International Journal of Innovations in Engineering and Science, www.ijies.net}

minutes are achieved by using $70 \mathrm{~g}$ of $\mathrm{R} 436 \mathrm{~A}$ with $\mathrm{L}=4.5 \mathrm{M}$, for CARE is achieved at pull-down time of 100minutes with $70 \mathrm{~g}$ and $\mathrm{L}=5 \mathrm{~m}$ and $\mathrm{R} 134 \mathrm{a}$ achieved as 110 minutes with $100 \mathrm{~g}$ and $4 \mathrm{~m}$. The performance has shown that the $\mathrm{R}$ 436 A refrigerant can be the best substitute to R134a.

Sunu et al. [8] compares the performance characteristics of a water chiller air conditioning simulation equipped with thermostatic expansion valve (TEV) with those of a capillary tube. Water chiller system filled with the same charge of refrigerant. Comparative analyses were performed based on coefficient of performance (COP) and performance parameter of the refrigeration system, carried out at medium cooling load level with the ambient temperature of $29-31^{\circ} \mathrm{C}$, constant compressor speed and fixed chilled water volume flowrate at $15 \mathrm{lpm}$. It was shown that the TEV system showed better energy consumption compared to that of capillary tube. From the coefficient of performance perspective, the thermostatic expansion valve system showed higher COP ( $\pm 21.4 \%$ ) compared to that of capillary tube system.

Rocha et al. [9] an algebraic solution to study adiabatic coiled capillary tubes in transcritical $\mathrm{CO}_{2}$ cycle was proposed. This solution evaluated three different friction factors and three possible $\mathrm{k}$ factors (related to the specific volume), with a total of nine combinations. A correlation to estimate the sand grain roughness was also proposed. To validate the algebraic solution, and to be useful for future studies, experimental tests were per- formed with two different capillary tubes, in a total of 60 points. The results showed that $95 \%$ and $98.3 \%$ of the predicted mass flow rates fell within $\pm 10 \%$ and $\pm 15 \%$ error bands, respectively, with average deviation (AD) and absolute average deviation (AAD) of $0.1 \%$ and $4.4 \%$, respectively. Overall, the C-M\&N (M\&N modified) friction factor performed better, however, the Schmidt friction factor was the only able to predict $100 \%$ of data within a $\pm 12 \%$ error band. An algebraic equation and a dimensionless correlation for straight capillary tubes were also adapted for the coiled shape, presenting a satisfactory performance. It could be concluded that the proposed solution was found to be an adequate tool for this application. To the best of the authors knowledge, an algebraic solution and experimental data for coiled capillary tubes in transcritical $\mathrm{CO} 2$ cycle are presented for the first time.

Zareh et al. [10] presents a drift flux model to simulate steady state refrigerant flow through horizontal lateral straight capillary tube-suction line heat exchangers with refrigerant $\mathrm{R} 134 \mathrm{a}$ as a working fluid. The geometry of capillary tube is divided into two regions: An entrance length and lateral heat exchanger length. Metastable flow phenomenon is neglected in this work. To better study of fluid behavior in non-adiabatic capillary tube, according to the refrigerant state at the entrance of heat exchanger region, three modes were studied and the fundamental equations were solved for all three modes, then the results were analyzed. The present data using a drift flux model were validated with previous numerical work with a homogeneous model with obtaining reasonable agreement. By considering the slip ratio effects in drift flux model, therefore, this model could able to predict refrigerant flow behavior more accurately than other two-phase flow models in non-adiabatic flow condition through capillary tube.

Sainath et al.[11] Capillary tube is one of the commonly used throttling devices in the refrigeration and the air conditioning systems. The capillary tube is made up of copper tube of very small internal diameter. It is of very long length and it is coiled to several turns so that it occupies less space. The internal diameter of the capillary tube used for the refrigeration and AC applications varies from 0.5 to $2.28 \mathrm{~mm}(0.020-0.09$ inches). Capillary tube used as the throttling device in the refrigerators, deep freezers, water coolers and air conditioners.

Ballester et al. [12] The subcooled condition at the condenser outlet ensures complete condensation, which is necessary in vapor compression systems to increase the cooling capacity and ensure the liquid conditions at the expansion device inlet. However, in household refrigerators, recent works indicate the presence of twophase flow at the capillary tube inlet. These systems behave quite differently from other refrigeration systems due to the extremely low capacity. In the present work, a test bench was built to visualize the refrigerant flow at the condenser outlet and at the capillary tube inlet of a commercial household refrigerator. A transparent tube replaced the end of the condenser and three transparent filters were installed with different orientations. Different positions of the capillary tube within the filters were also tested. Despite measuring a certain sub cooling, all the reported visualizations showed that the capillary tube was steadily drawing in two-phase flow. 


\section{International Journal of Innovations in Engineering and Science, www.ijies.net}

Lara et al. [13] comes out with an experimental investigation of the expansion of refrigerant HFC-134a through adiabatic capillary tubes with internal diameters ranging from $0.23 \mathrm{~mm}$ to $0.53 \mathrm{~mm}$ aiming at the so-called mesocooling applications. To this end, an experimental apparatus was designed and constructed to emulate the operating conditions of mesoscale refrigerating devices, with condensing pressures ranging from 9 to 19 bar, and inlet refrigerant subcooling ranging from 5 to $10 \mathrm{~K}$. The tube length was varied from 1 to $2 \mathrm{~m}$. The tests were carried out following a factorial design. The experimental data were used to assess the mass flow rate prediction capabilities of an explicit, algebraic model for adiabatic capillary tubes devised in a prior work. The results revealed that the model is not suitable for small-bore capillary tubes. Correction factors were proposed, so that the model predictions for more than $90 \%$ of the experimental dataset fell within $\pm 10 \%$ error bounds.

Salem et al. [14] experimentally investigates the effect of the geometrical parameters of a vertical conically coiled tube-in-tube (CCTIT) evaporator/condenser and their operating conditions on their effectiveness and on the coefficient of performance (COP) of a vapor compression refrigeration system (VCRS). Twelve CCTIT evaporator/condenser of different taper angles $\left(0-135^{\circ}\right)$ and torsions (0.0777-0.1311) are tested for different water Dean numbers in their annuli, while R134a flows in their internal tube in a counter flow configuration. The results show that increasing the evaporator/condenser taper angles and torsions in addition to decreasing their water Dean numbers augment the evaporator/condenser effectiveness and the COP of the VCRS. However, the coils taper angles have the more dominant effect than the other studied parameters. Finally, experimental correlations are developed to predict the COP of the VCRS in addition to the effectiveness of both the evaporator and condenser as functions of the investigated parameters.

Abed and Fatehi [15] presents an experimental investigation of metastable region take place for refrigerant flow through adiabatic and non-adiabatic capillary tube of window type air conditioner. Large numbers of experiments are carried out to explain the effect of length of straight and helical capillary tube on metastable region under adiabatic and non-adiabatic conditions. for the case of adiabatic capillary tube, three different length are selected(70,100 and 150) $\mathrm{cm}$ and two helical capillary tube, the length of each tube is $100 \mathrm{~cm}$ with two coil diameters (2 and 6) $\mathrm{cm}$. For the non-adiabatic capillary tube, the straight capillary tube suction line is $150 \mathrm{~cm}$ while the length of non-adiabatic helical capillary tube is $200 \mathrm{~cm}$ with $8 \mathrm{~cm}$ coil diameter. The results show that the length is the most influence parameters on beginning of metastable region. In addition the helical coil tube effect on the beginning of metastable region. As well as for the adiabatic and non-adiabatic capillary tube it is concluded that mass flow rate is the main parameters on beginning of metastable region. Also effect of length and coiling on both pressure drop and mass flow rate are discussed. The CFD commercial code, ANSYS CFX 16.1 based on finite volume method using $\mathrm{K}$ turbulence model considering the homogeneous flow between phases applied to straight capillary tube. The present numerical data has been validated with the present work experimental data and with other researchers. A good agreement is obtained which can be lead to use ANSYS CFX 16.1 in the design and optimization of capillary tube in air conditioner.

Neelakanta et al. [16] design of capillary tube plays a very important role in the performance of a vapour compression refrigeration system. Optimized design is possible through theoretical calculations, however may fail due to the reason that the uncertainties in the formulation of pressure drop inside the capillary tubes. Hence experimental investigations are the best in terms of optimization of certain design parameters. Components of the vapour compression refrigeration system never work in isolation; change in performance of one component affect the performance of the other components and in turn overall performance of the system. Performance of the system also depends on the type, quantity of the refrigerant charged. In the present work, an attempt is made to optimize Length of capillary tube for refrigeration unit of capacity 301ts; with R-134a as refrigerant and hermetic sealed compressor of capacity 0.14 H.P. and this study examined the effects of lengths capillary tubes on the performance of a vapor compression refrigeration system. It is found that 4.5 feet Length of capillary tube gave a better performance. Both inlet and outlet pressure and temperature of the test section (capillary tube) were measured and used to estimate the coefficient of performance (COP) of the system. The parameters stated above can be further optimized in order to enhance the performance of the refrigeration system. 


\section{International Journal of Innovations in Engineering and Science, www.ijies.net}

Ajayi et al. [17] investigated the flow of nano refrigerants through adiabatic capillary tubes of vapour compression refrigeration systems; and afterwards creates numerical models that will account for solution of refrigerant side pressure drop and mass flow rate. Also in this study, a CFD flow analysis was carried out using a CFD simulation/solver such that the results of the simulations obtained were discussed so as to establish a distinction between the conventional and nano-refrigerants. Upon comparison of the CFD results of nano-refrigerants (CuR134a, CuR600a) and the conventional refrigerants (R134a, R600a), the conventional refrigerants were noticed to have more isothermal regions implying that heat was not being transferred quickly enough to raise the temperature of the adjoining region thus proving that the addition of nanoparticles improves the thermos-physical properties of the base fluid. Also, based on the results of the study of the flow patterns of both working fluids, the density of pressure contours in the conventional refrigerants was far larger than that of the nano-refrigerant implying that more compressor work and ultimately greater power will be required. The findings from this study were validated with experimental results showing that a CFD analysis tool/method can be employed to understudy the phenomenal changes that take place in nano-refrigerant movement through capillary tubes without recourse to experimentation.

Alok and Sahu [18] investigated an attempt is made to analyze the flow of Isobutane (R-600a) inside the coiled capillary tubes for different load conditions by Homogeneous Equilibrium Model. The Length and diameter of the capillary tube not only depend on the pressure and temperature of the condenser and evaporator but also on the cooling load. The present paper investigates the change in dimensions of the coil capillary tube with respect to the change in cooling load on the system for the constant condenser and evaporator conditions. ANSYS CFX (Central Florida Expressway) software is used to study the flow characteristics of the refrigerant. Appropriate helical coil is selected for this analysis.

Bardoulet et al. [19] works have indicated that even when measuring subcooled conditions at the condenser outlet, the condition at the capillary tube inlet is a two-phase flow. The present work was dedicated to analyzing the actual refrigerant conditions at the capillary tube inlet and to investigating how full liquid conditions could be achieved.
The research was performed using a typical household refrigerator with corresponding fresh food and freezer compartments, replacing the original refrigerant-to-air condenser with a refrigerant-to-water condenser. This allowed, first, the condensation conditions to be controlled and, second, the estimation of the refrigerant conditions at the condenser outlet from the heat exchanger balance. The obtained results indicated the presence of a non-equilibrium two-phase flow, composed of subcooled vapor and subcooled liquid, at the capillary tube inlet, with both liquid and vapor entering the capillary tube as a vortex with small, fast fluctuations of the liquid level. This non-equilibrium indicated that the sub cooling, evaluated from the pressure and temperature of the refrigerant at the condenser outlet, was only apparent and did not allow the evaluation of the actual enthalpy. Finally, by using a smaller capillary tube diameter and increasing the compressor speed, full liquid conditions at the capillary tube inlet were achieved. Furthermore, a performance comparison between the original and the new design revealed that the COP was higher with full liquid conditions.

\section{III-CONCLUSION}

The present study reviewed the effect of different size and diameters of capillary tube on vapor compression refrigeration system. The research was conducted on different refrigerants and capacity of system. But it has been seen that, helical coil capillary tube gives higher performance than straight tube but the optimum length and diameter size will vary with respect to capacity of system. The CFD analysis is very helpful to determine the optimum diameter and length.

\section{REFERENCES}

[1] Kulmitra, "Ijesrt International Journal of Engineering Sciences \& Research Technology Numerical Investigation of Capillary Tube By Replacing the Inside Refrigerant and Diameter," Int. J. Eng. Sci., vol. 5, no. 7, pp. 102-114, 2016.

[2] Y. R. Kumar and P. U. Sri, "CFD Flow Analysis of a Refrigerant inside Adiabatic Capillary Tube," vol. 2, no. 9, pp. 485-493, 2013.

[3] C. Kumar, "Enhancement of Coefficient of Performance by Analysis of Flow through Vapour Compression 


\section{International Journal of Innovations in Engineering and Science, www.ijies.net}

Refrigeration cycle using CFD," vol. 2, no. 6, pp. 6672, 2015, doi: 10.17148/IARJSET.2015.2616.

[4] B. Chouhan, P. P, and S. Kumar, "Analytical Investigation of R134a Flowing Through Adiabatic Helically Coiled Capillary Tubes," Iarjset, vol. 4, no. 2, pp. 139-144, 2017, doi: 10.17148/iarjset.2017.4232.

[5] A. Kulmitra, N. Yadav, A. Tiwari, and A. Dewangan, "Comparative Study of Capillary Tube by Changing Refrigerant and Diameter of Tube by Experimental and CFD Analysis," vol. 5, no. 10, pp. 487-490, 2017.

[6] S. O. Oyedepo et al., "A comparative experimental study on performance of domestic refrigerator using R600A and LPG with varying refrigerant charge and capillary tube length," 30th Int. Conf. Effic. Cost, Optim. Simul. Environ. Impact Energy Syst. ECOS 2017, vol. 18, no. 4, pp. 287-302, 2017.

[7] D. V. R. Reddy, P. Bhramara, and K. Govindarajulu, "Experimental Evaluation of the Effect of Refrigerant Charge and Capillary Tube Length on the Performance of Household Refrigerator with Different Configurations of R290 and R600a," Mater. Today Proc., vol. 5, no. 5, pp. 11845-11852, 2018, doi: 10.1016/j.matpr.2018.02.155.

[8] P. W. Sunu, I. Made Rasta, D. S. Anakottapary, I. Made Suarta, and I. D. M. Cipta Santosa, "Capillary Tube and Thermostatic Expansion Valve Comparative Analysis in Water Chiller Air Conditioning," J. Phys. Conf. Ser., vol. 953, no. 1, 2018, doi: 10.1088/17426596/953/1/012063.

[9] T. Torres Martins Rocha, C. Henrique de Paula, J. Jose Garcia Pabon, T. de Freitas Paulino, and R. Nunes de Oliveira, "Algebraic solution and experimental validation for adiabatic coiled capillary tubes operating in transcritical CO2 cycle," Appl. Therm. Eng., vol. 181, no. July, p. 115930, 2020, doi: 10.1016/j.applthermaleng.2020.115930.

[10] M. Zareh, M. Khayat, and H. Fouladi, "Numerical simulation of two phase refrigerant flow through nonadiabatic capillary tubes using drift flux model," J. Mech. Sci. Technol., vol. 32, no. 1, pp. 381-389, 2018, doi: 10.1007/s12206-017-1238-2.

[11] K. Sainath, T. K. Kumar Reddy, and S. Akella, "Optimization of capillary tube dimensions using different Refrigerants for 1.5 ton mobile air conditioner," Case Stud. Therm. Eng., vol. 16, no.
September 2017, p. 100528, 2019, doi: 10.1016/j.csite.2019.100528.

[12] S. Martínez-Ballester, L. Bardoulet, A. Pisano, and J. M. Corberán, "Visualisation de l'écoulement $d u$ frigorigène à l'entrée $d u$ tube capillaire d'un réfrigérateur domestique à haute efficacité," Int. J. Refrig., vol. 73, pp. 200-208, 2017, doi: 10.1016/j.ijrefrig.2016.09.019.

[13] J. F. P. de Lara, C. Melo, J. Boeng, and C. J. L. Hermes, "Experimental analysis of HFC-134a expansion through small-bore adiabatic capillary tubes," Int. J. Refrig., vol. 112, pp. 37-43, 2020, doi: 10.1016/j.ijrefrig.2019.12.015.

[14] M. R. Salem, H. A. El-Gammal, A. A. Abd-Elaziz, and K. M. Elshazly, "Study of the performance of a vapor compression refrigeration system using conically coiled tube-in-tube evaporator and condenser, " Int. J. Refrig., vol. 99, pp. 393-407, 2019, doi: 10.1016/j.ijrefrig.2018.12.006.

[15] E. M. Abed and A. A. K. Fathi, "Experimental and Numerical Investigation of Metastable Flow of Refrigerant R-22 Through Capillary Tube," Iraqi J. Mech. Mater. Eng., vol. 18, no. 1, pp. 41-62, 2018, doi: 10.32852/iqjfmme.voll8.iss1.72.

[16] N. V. M. K. K. Neelakanta, V. Arundhati, "Effect of capillary tube on the performance of a simple vapour compression refrigeration system," IOSR J. Mech. Civ. Eng., vol. 11, no. 3, pp. 05-07, 2014, doi: 10.9790/1684-11310507.

[17] O. O. Ajayi, D. E. Ibia, M. Ogbonnaya, A. Attabo, and A. Michael, "CFD Analysis of Nanorefrigerant through Adiabatic Capillary Tube of Vapour Compression Refrigeration System," Procedia Manuf., vol. 7, pp. 688-695, 2017, doi: 10.1016/j.promfg.2016.12.102.

[18] P. Alok and D. Sahu, "FLOW ANALYSIS of ISOBUTANE (R-600A) INSIDE AN ADIABATIC CAPILLARY TUBE," IOP Conf. Ser. Mater. Sci. Eng., vol. 310, no. 1, 2018, doi: 10.1088/1757. 899X/310/1/012148.

[19] L. Bardoulet, J. M. Corberán, and S. MartínezBallester, "How to achieve full liquid conditions at the capillary tube inlet of a household refrigerator, " Int. J. Refrig., vol. 100, pp. 265-273, 2019, doi: 10.1016/j.ijrefrig.2019.02.006. 